University of Wollongong

Research Online

Faculty of Social Sciences - Papers (Archive) Faculty of Arts, Social Sciences \& Humanities

$1-1-2018$

Sustainability and Scalability in Educational Technology Initiatives:

Research-Informed Practice

Dale Niederhauser

West Virginia University

Sarah Katherine Howard

University of Wollongong, sahoward@uow.edu.au

Joke Voogt

University of Amsterdam

Douglas Agyei

University of Cape Coast

Therese Laferriere

University of Laval

See next page for additional authors

Follow this and additional works at: https://ro.uow.edu.au/sspapers

Part of the Education Commons, and the Social and Behavioral Sciences Commons

Research Online is the open access institutional repository for the University of Wollongong. For further information contact the UOW Library: research-pubs@uow.edu.au 


\title{
Sustainability and Scalability in Educational Technology Initiatives: Research- Informed Practice
}

\author{
Abstract \\ Although a positive impact of technology interventions on educational practice and student outcomes \\ has been shown in many previous research settings, the use of technology in classrooms and schools is \\ still often superficial and not meeting the potential of technology as envisioned by education reformers \\ and researchers in the field. However, when technology projects have been implemented successfully in \\ educational practice and shown valuable impacts, sustainability within similar contexts is not guaranteed- \\ let alone scaling the initiative to other broader contexts. This article builds on the discussions of the \\ EDUsummIT 2017 Thematic Working Group 9 (TWG9) and the summary report that captured the outcome \\ of those discussions. The goal of TWG9 was to help inform policy and practice by providing insights into \\ key factors that contribute to scalability and sustainability of educational technology integration and \\ impact.

\section{Disciplines} \\ Education | Social and Behavioral Sciences

\section{Publication Details} \\ Niederhauser, D. S., Howard, S. K., Voogt, J., Agyei, D. D., Laferriere, T., Tondeur, J. \& Cox, M. J. (2018). \\ Sustainability and Scalability in Educational Technology Initiatives: Research-Informed Practice. \\ Technology, Knowledge and Learning, 23 (3), 507-523.

\section{Authors} \\ Dale Niederhauser, Sarah Katherine Howard, Joke Voogt, Douglas Agyei, Therese Laferriere, Jo Tondeur, \\ and Margaret J. Cox
}




\title{
Sustainability and Scalability in Educational Technology Initiatives: Research-Informed Practice
}

\author{
Dale S. Niederhauser ${ }^{1}$. Sarah K. Howard ${ }^{2}$. Joke Voogt ${ }^{3}$ - Douglas D. Agyei ${ }^{4}$. \\ Therese Laferriere $^{5}$. Jo Tondeur ${ }^{6} \cdot$ Margaret J. Cox $^{7}$
}

Published online: 21 August 2018

(c) Springer Nature B.V. 2018

\begin{abstract}
Although a positive impact of technology interventions on educational practice and student outcomes has been shown in many previous research settings, the use of technology in classrooms and schools is still often superficial and not meeting the potential of technology as envisioned by education reformers and researchers in the field. However, when technology projects have been implemented successfully in educational practice and shown valuable impacts, sustainability within similar contexts is not guaranteed-let alone scaling the initiative to other broader contexts. This article builds on the discussions of the EDUsummIT 2017 Thematic Working Group 9 (TWG9) and the summary report that captured the outcome of those discussions. The goal of TWG9 was to help inform policy and practice by providing insights into key factors that contribute to scalability and sustainability of educational technology integration and impact.
\end{abstract}

Keywords Technology integration $\cdot$ Sustainability $\cdot$ Scalability $\cdot$ Cases

\section{Introduction}

The education sector has been engaged in 30 years of educational technology initiatives, venture funding for educational technology has been rising (Koba 2015), and expenditures for educational technology have topped \$6.5B in 2015 for the US alone (McCandless 2015). Yet many would agree that there have been limited returns on these

Dale S. Niederhauser

dsniederhauser@mail.wvu.edu

1 College of Education and Human Services, West Virginia University, P.O. Box 6122, Morgantown, WV 26506, USA

2 University of Wollongong, Wollongong, Australia

3 Universiteit van Amsterdam, Amsterdam, Netherlands

4 University of Cape Coast, Cape Coast, Ghana

5 Universite Laval, Quebec, Canada

6 Vrije Universiteit Brussel, Brussels, Belgium

7 King's College London, London, UK 
substantial financial investments, with regard to positive impact on learning (Cuban 2002; Kirkwood and Price 2013; Reeves and Reeves 2015). Specifically, the sustained efforts to motivate teachers to integrate digital technologies and develop effective uses of technologies in learning have not lived up to popular expectations.

The desire of many technology-related change initiatives has been to encourage reform-oriented technology integration grounded in inquiry and drawing on cognitive and constructivist learning principles (see Fishman et al. 2004; Jonassen 1995). This would include features like online communication and social interaction, collaboration, use of authentic contextualized activities, and reflection on learning. These aspects of digital technology use are important parts of effective integration, as technology integration is more likely to have a positive impact on learning when these are taken into consideration in digitally integrated learning designs (see Livingstone 2012). However, in a recent Pew Research Center survey, less than half (40\%) of US teachers allowed students to develop, share, or post work on a website, wiki, or blog. Only $39 \%$ of teachers allowed students to participate in online discussions, and only $22 \%$ of teachers allowed students to post projects online where someone other than their teachers or classmates could see it (Purcell et al. 2013).

The minimal influence of educational technology initiatives on pedagogical practices has made it clear that simply providing access to technology is not sufficient to address the kinds of pedagogical change hoped for by reformers (Niederhauser and Lindstrom 2018). While reaching a critical mass of hardware, software, and infrastructure was necessary for meaningful levels of technology integration to occur, educators, researchers, and policy-makers have long recognized that technology integration is an extremely complex process with multiple interacting factors including curricular, pedagogical, technological, individual and organizational considerations (Howard and Thompson 2016; Sherry 1998). However, it is important to understand that it technology integration is only limited in some contexts, and there have been a number of significant and successful technologyrelated change initiatives, such as the Maine Learning Technology Initiative (DOE 2018), the iconic Apple Classrooms of Tomorrow project (Sandholtz and Ringstaff 1996) and the on-going Intel Teach courses (Intel 2018). These three programs have addressed state-level one-to-one laptop use, multi-date technology integration and professional development, and international technology-related teacher professional development, respectively. Each of these programs has been scalable in different contexts and sustained over time.

The complexity of interacting factors impacting on scalability and sustainability raises numerous challenges relating to technology integration initiatives and innovation. In this discussion sustainability is understood as ongoing change. Scalability is understood as the dissemination of change across different contexts. These are key characteristics for successfully integrating information and communication technologies (ICT) in education (Albion et al. 2015; Voogt et al. 2015). Sustainable instructional innovations are likely to become richer, more nuanced and complex as they are embedded in and adapted to educational contexts over time. In this process, teachers and schools invest time in the innovation to fit it to their context. For example, as a teacher becomes more familiar with the affordances of a particular digital technology, how they integrate the tool will become more specialized and suited to their own teaching and students (e.g. Howard and Gigliotti 2016). Simultaneously, as innovations are scaled and introduced in new contexts, they often mutate and change to address and fit with local needs and demands of the new space-which can dilute the effectiveness of the innovation. This "reinvention" process (Rogers 2003, p. 180) creates a clear tension between user-adaptation and fidelity-of-innovation implementation across contexts (Penuel et al. 2011). 
It is important to understand the critical role of context and the significant variability that exists among educational systems and structures. The deepest understanding of a given educational context is often held by key stakeholders. At the school level, this would be teachers, principals, students and parents; at the district level superintendents, and instructional and curricular directors; at the government level, policymakers, education advisors and lobbyists; and finally, partners from the technology business and industry sector. Each of these groups has knowledge of the values, beliefs and practices related to technology integration at a given level. This knowledge can provide insights into the adoption and diffusion process. To establish meaningful integration of digital technologies in schools, it needs to be a joint effort among teachers and school leadership, researchers, policymakers and industry partners when designing, implementing disseminating and sustaining researching technology integration efforts.

Our goal in this paper is to illuminate some of the issues facing these stakeholders who seek scalable and sustainable integration of technology within and across complex school contexts. This effort builds on the discussions of the EDUsummIT 2017 Thematic Working Group 9 (TWG9) and the summary report that captured the outcome of those discussions (Niederhauser et al. 2017). The goal of TWG9 was to help inform policy and practice by providing insights into key factors that contribute to scalability and sustainability of educational technology integration. Specific objectives of the working group were to:

1. Identify key challenges that influence sustainability and scalability of educational technology initiatives;

2. Provide recommendations to address those challenges;

3. Provide illustrative cases that highlight how some of the key factors manifest.

In the remainder of this paper we will examine key concepts, models and frameworks from the sustainability and scalability literature that can inform technology integration efforts. We then provide four cases as examples of collaborative partnerships among multiple stakeholders that promote diffusion and persistence of technology integration efforts over time. We conclude with a discussion of the importance of these partnerships to better understand the educational context and how it impacts sustainability and scalability. We argue that thoughtful and purposeful research-driven integration efforts that draw on stakeholder partnerships are key to supporting sustainability and scalability of educational technology initiatives. This is an alternative perspective to the trendy political mandate-driven technology educational change, which, although common practice, typically does little to promote long-term systemic change.

\section{Background}

\subsection{Sustainability}

Educational technology initiatives that are sustained over time are characterized by persistent and ongoing change of the educational culture. This happens when necessary support systems and resources are in place, and the improvement that the innovation is aiming for is accepted by all and maintained over time. However, it is often difficult to sustain innovations in the face of competing priorities, ever-changing and competing demands, and ongoing turnover in the administrative and teaching workforce 
(Hargreaves and Fink 2000). Several factors play into the sustainability of change, including the innovation adoption process, leadership and the need for ongoing support and access to resources, and strong relationships among stakeholders.

Clearly teachers' beliefs about digital technologies and integration in learning plays a central role in diffusion and adoption of ICTs in schools (Ertmer and Ottenbreit-Leftwich 2010). Diffusion of Innovation (Rogers 2003) has informed our understanding of how innovative uses of technology are adopted by teachers. Rogers' model, proposes several stages that adopters may progress through:

- Knowledge: Becoming aware of the innovation;

- Persuasion: Becoming knowledgeable about the characteristics of the innovation;

- Decision: The process involved in deciding to adopt or reject the innovation;

- Implementation: Putting the new idea or technology into practice;

- Confirmation: Reflecting on the decision and implementation experience to decide whether to continue or discontinue adoption of the innovation.

While the process of change is generally complex and non-linear, these components provide a framework to understand some of the major points to consider in the process. The decision, implementation and confirmation stages represent key points in the iterative cycle. In the process of adoption, teachers will reevaluate the degree and manner to which educational technology initiatives are implemented-balancing perceived usefulness with fidelity of implementation. Harvey and Hurworth (2006) argued an interactive relationship between sustainability and adoption of innovations, as innovations evolve over time through modification based on teachers' needs and expectations (see Dede 2006). Rogers (2003) highlights how personal relationships and communication patterns, interpersonal connections among change agents (p. 365), opinion leaders (p. 27) and champions (p. 414) drive diffusion at the local level. As innovations continue to diffuse through a context, they are adapted by individuals and become increasingly sustainable.

Other key factors include the importance of leadership and support (e.g. Bebell and O'Dwyer 2010; Dickard 2003). Much has been written about the importance of administrative leadership in implementing and sustaining reform initiatives (see Fullan 2015; Hargreaves et al. 2014), and it is well known that effective school leaders are key to effective implementation of large-scale, sustainable education reform efforts (Fullan 2009). Further, a broad base of support, including support for teachers, principals, students and parents, as well as supportive policies and financial resources, is deemed essential for sustaining reform (Owston 2003). Eickelmann (2011) found support for teachers was especially important when bolstered by teachers' participation in decision-making with regard to implementing initiatives. In addition, Fishman et al. (2004) observed that to keep the technological infrastructure in schools up to date, schools can partner with organizations outside the traditional educational infrastructure (e.g. Gao and Murphy 2016).

During TWG9 discussions, the importance of involving what Dickard (2003, p. 37) referred to as a "broad coalition of stakeholders" early on in the planning and implementation process was emphasized. Once established, strong collaborative relationships among school-level administrators and educators, and researchers and policymakers who often initiate and support reform initiatives, must be maintained throughout the implementation process as innovations as adopted (see Rogers 2003, p. 428) and embedded in the culture of the school. Thus, planning for sustainable change requires involvement of multiple stakeholders at the start—and throughout the change process (Greenhow et al. 2009). 


\subsection{Scalability}

Scalability is the likelihood that an innovation will diffuse effectively across a culture/ context. In 1998, Stringfield and Datnow (1998) defined scaling in the context of educational change as 'the deliberate expansion to many settings of an externally developed school restructuring design that previously has been used successfully in one or a small number of school settings' (p. 271). However, more recently it has been acknowledged that a change initiative can be implemented from inside a school or community of practice (e.g. Wei, Darling-Hammond et al. 2009) and that only addressing quantity is an oversimplified perspective on scalability. Wiske and Perkins (2005) also warn against "the replica trap," which is the assumption that innovations are not dependent on local variations. In fact, successful change in one context might have very different results in other contexts. Stringfield and Datnow's definition ignores this complexity and the importance of context.

In her seminal article, Coburn (2003) proposed a multidimensional view of scalability that distinguished between depth, sustainability, spread and shift in ownership. This approach supports inquiry across contexts to address issues of scalability and making change relevant in different schools (e.g. Fleener 2016). Depth refers to an understanding of the essential characteristics of the innovation. According to Coburn, this often requires teachers to change their pedagogical practices and their beliefs about what constitutes "good education." Sustainability, as discussed above, involves the maintenance of change over time, while spread addresses the diffusion of an innovation to different contexts. Shift of ownership relates to the need for the innovation to be owned by all involved stakeholders, and that different stakeholders will assume primary responsibility for the initiative over time. Clarke and Dede (2009) extended Coburn' framework to include evolution. Evolution refers to the way stakeholders use, adapt and implement the innovation in their local contexts. This also impacts the way the designers see the innovation. Evolution thus suggests that the innovation develops because of the interaction between the users and the designers of the innovation.

Thus, dissemination of educational innovations is not only about quantity, but also about the multidimensional factors introduced above. There is quite a bit of overlap between sustainability and scalability, as it is often viewed that sustainability is a necessary condition for scalability (Clarke and Dede 2009; Coburn 2003). Attending to sustainability issues is essential in bringing educational innovations to scale, and it is important to work closely with teachers and schools to identify the support and tools that are needed to sustain and scale innovations. The TWG9 group begun the process of developing a framework to support the research community to better support and promote sustainable and scalable educational technology initiatives.

\subsection{Challenges to Sustainability and Scalability}

In response to Objective 1, TWG9 members identified three challenges that were deemed central to addressing scalability and sustainability issues:

Challenge 1: Identify key features of research-informed approaches to technology integration that are sustainable and scalable;

Challenge 2: Establish productive partnerships among stakeholders; 
Challenge 3: Develop sustainable and scalable approaches to technology integration that are based on impact found in research literature rather than isolated politically-driven policy initiatives.

In the following section four international research cases are presented. All four address recent efforts to diffuse educational technology initiatives in challenging contexts. These cases help illustrate some of the key sustainability and scalability factors that were discussed above.

\section{Cases of Technology Integration from Australia, Ghana, Tanzania and Canada}

\subsection{Australia: Scalability and Sustainability of a Large-Scale Technology Innovation in Secondary Schools: The Case of the Australian Digital Education Revolution}

\subsubsection{Case Vignette}

In 2008, the Australian federal government initiated a national policy to provide all secondary (Years 9-12) students and teachers with new and upgraded information and communication technologies (ICTs; Department of Education Employment and Workplace Relations 2012). The overarching aim of the initiative was to insure students and teachers had the same access to digital technologies necessary to support learning and prepare students for full participation in future society. The initiative, called the Digital Education Revolution (DER), was active from 2009 to 2014. It was implemented at the state-level, and at the school level within each of the states. Five case-study schools in the state of New South Wales (NSW) participated in a program evaluation and research project between 2010 and 2013. The DER manifested differently in each of the teaching and learning contexts and with varying levels of success, illustrating the core tension of fidelity of innovations across contexts. Teacher and school leaders found the reflective nature of the research, specifically interviews, focus groups and observations, a useful way to examine engagement and sustainability of change in the initiative. This also suggests the value of strong researcher and stakeholder partnerships in technological innovations, in particular in creating a feedback loop on progress and future intentions.

\subsubsection{Focus}

The aim of the research was to understand how different schools negotiated the Digital Education Revolution initiative in New South Wales, to examine any impact on teaching and learning and change in practice. Five schools participated as case studies. Schools were selected based on a composite 'engagement' score, based on questionnaire responses in 2010. Each case study included annual completion of: teacher, student and parent questionnaires; teacher, student and school leader interviews; teacher and student focus groups; and, classroom observations, over 4 years. The research focused on key stakeholders' perceptions of and engagement with the DER program, integration of digital technologies in teaching and learning, and how this changed over the 4 years. The study specifically focused on beliefs about technology integration (e.g. Ertmer and Ottenbreit-Leftwich 2010), confidence using digital technologies (e.g. Howard 2011; Teo and Noyes 2008), 
technology leadership (e.g. Dunleavy et al. 2007) and experiences in the DER program (e.g. Van Veen and Sleegers 2006).

\subsubsection{Discussion of Findings}

In NSW, the state education department decided to provide all Year 9 students and fulltime teachers with personal laptops, starting in 2009. Overall, use of these laptops in teaching and learning slowly increased in frequency and quality over the 4 years. In 2013, laptop integration was significantly more frequent and teachers were feeling more confident designing integrated lessons.

Several key factors of program sustainability were observed. Of the five case study schools, three schools began preparing for the laptops before their arrival. These schools were more likely to have a 'technology committee' to guide program implementation in their context. These were approaches adopted by school leadership. Often, the five schools would have members of the technology committee participate in the research project, as a method of communicating how the program was implemented at their school. Considering Rogers' model, teachers at those schools had better knowledge of the innovation and were able to more confidently make decisions about adopting the laptops in their classroom and across the school. Successful and early adoption of the program was more likely with these two factors of sustainability in place. Other key factors of sustainability were quality professional learning experiences and personalized in-school support. In one of the schools, teachers were given a high level of autonomy in choice of professional development and release time to work on teaching materials focusing on use of the laptops. Three of the five schools formed a consortium that shared a full-time technology integration support person. This person travelled between the three schools, organizing one-on-one appointments with teachers to work on anything they wished relating to technology integration. In both cases, teachers were able to identify their own learning needs and easily access support resources.

However, sustainability was also significantly put at risk in several ways. The first was the laptop device itself. Teachers and students found it difficult to use because it was slow, the battery ran down quickly, and it did not maintain a reliable Internet connection. Many teachers and students had a strong negative view of the DER program which limited adoption and therefore sustainability of the DER program. There was also lack of commitment at the federal and state levels to continue the program beyond 2014. This had a significant impact on teachers' willingness to implement new practices, and added time and effort into developing new teaching resources, if the laptops would not be available the following year.

Scaling of practices through evolution was observed through the creation of small technology policies requiring use of the laptops. Small policies provide stepping stone for teachers to adopt digital technology, but it is only a small change in their practice. Therefore, it is implementing new practices, but in a way that is sensitive to the local context and can lead to more complex practices. Examples of these small policies include: expecting all worksheets to be available as PDFs, having all school communication go through email, and requiring electronic attendance for each class. These practices help teachers change their habits and take ownership of the innovation. At a state-level, extensive online resources and professional development opportunities were offered to teachers. Training was aimed at shifting their pedagogical approach to teaching with the laptops to more student-centered strategies. This was an essential characteristic of the DER and attempted to 
affect the depth of change across the state. Results from the research did not find a significant change in teachers' reported pedagogical approach.

In summary, aspects of the DER program that could be adapted or modified did not limit sustainability or scalability. Components of a program, such as the laptop device and pedagogical approach, which could not be changed or were very difficult to change were barriers. However, with key leadership and support for teachers' professional learning these issues can be overcome. This also required a significant time commitment from stakeholders. If they did not feel their time and input was worthwhile and valued, as with questions about longevity of the DER program, teachers questioned whether they should contribute their time to learn and design teaching materials around new technologies. This suggests that careful consideration needs to be taken to analyze technology innovations to identify if key components are too rigid and will limit change in different contexts. While these are often difficult to anticipate, close researcher and stakeholder partnerships could help to identify these components early in implementation.

\subsection{Ghana: Examining Factors Affecting Beginning Teachers' Transfer of Learning of ICT-Enhanced Learning Activities in Their Teaching Practice}

\subsubsection{Case Vignette}

Ghana introduced digital technologies into the school curriculum in September 2007 and since then has highlighted the importance of integrating ICT into the curriculum at all levels. The new curriculum in Mathematics at the senior high school (Years 11 and 12) encourages teachers to make use of computers for problem solving and investigations of real life situations. The aim of this was to help students develop analytical thinking habits and the capacity to apply knowledge in solving practical problems. To support this aim, the government and other institutions invested large sums of money to procure computers and establish computer labs in an effort to scale this use across most senior high schools nationwide. However, it was unclear whether these efforts had a broad and sustained effect on teachers' appropriate use of computers in their instruction.

To insure teachers were prepared to deliver the new curriculum, it was necessary to address Mathematics training at the pre-service teacher level. This required scaling this new orientation to ICT-supported mathematics teaching and learning in university teacher training programs across Ghana. In 2009, a government initiative was launched to begin this process. Progressive data on the initiative was collected at three points $(2009,2010$ and 2011). The initiative comprised a professional development program, in which students were introduced to collaborative design principles, to prepare final year pre-service teachers to integrate ICT in teaching mathematics in a teacher education institute (Agyei 2012; Agyei and Voogt 2011). The ICT-based innovation consisted of two related components: (1) learning of technology by collaborative design (LTCD) (process) and (2) ICTenhanced activity-based lessons in mathematics (ICT-ABL) (product). In early 2011, the approach was applied to a regular mathematics-specific instructional technology course at the teacher education institute (Agyei 2012).

\subsubsection{Focus}

Approximately 6, 18, and 28 months after the three interventions respectively, pre-service mathematics teachers who participated in the studies had been posted into various senior 
high schools and were pursuing their careers as mathematics teachers. The study employed an embedded mixed-method research design to examine the extent to which 100 of the pre-service teachers were able to transfer the knowledge and skills gained during their preservice training and utilize the ICT-based innovation with their students. A follow-up study was conducted to determine how well they continued to use ICT knowledge and skills learned as preservice teachers. Based on Baldwin and Ford (1988), the study postulated transfer of learning as a function of: (1) characteristics of the ICT-based innovation; (2) beginning teachers' learner characteristics and (3) school environment characteristics. The study sought to understand how these characteristics influenced transfer of learning in the teachers' professional and teaching practice.

\subsubsection{Discussion of Findings}

The findings showed that pre-service teachers still held positive pedagogical views developed during collaborative design in teams in their pre-service teacher preparation program. This suggests increased depth and possible sustainability, and through a deep understanding of the innovation. This seemed to be the most influential factor on teachers' transfer and continuous use of the innovation. The second most influential factor affecting teachers' continued use of the ICT-based innovation was their learner characteristics. However, sustainability was strongly affected by the amount of variance attributed to the teachers' knowledge and persuasion related to the innovation, specifically learner characteristics related to adoption of the new practices and transfer. The most critical learner characteristics reported were knowledge and skills related to ICT use. It was encouraging to note that most beginning teachers reported having sufficient knowledge and skills, which was an indication of how well the preparatory program contributed to teachers' professional learning. These factors suggest scalability of the initiative. However, school environment factors were not a significant predictor of transfer of learning, probably because of lack of variation in the school-related factors across the schools. However, interview and observation data indicated that teachers were faced with constraints related to their school environment that contributed to lack of creativity in using certain components of the ICT-based innovation. Particularly, lack of access to the ICT infrastructure and an unenthusiastic school culture were mentioned as hindering the use of ICT-ABL.

In conclusion, the study revealed that scalability, as related to sustainability although a significant amount of variation in the transfer of learning and the utilization of the ICTbased innovation could be attributed to the teacher-related factors in the context. The role of school environment plays an important role in influencing transfer of learning in beginning teachers' professional and teaching practice was a central issue. The professional development that these teachers experienced in their preservice preparation program was an important factor in scaling and sustaining this new orientation to ICT-supported mathematics teaching. Todorova and Osburg (2009) argue that professional development programs aiming to realize the sustainable uptake of ICT in teaching and learning can only be successful when the involved teachers have positive attitudes and are satisfied with the program, when the reasoning for using ICT to improve teaching and learning practices is accepted by a large proportion of the teachers in the participating schools, and not only by those who participated in the program, and when institutional support and resources in implementing the goals, content and practices learned during professional development is available (Todorova and Osburg 2009). 


\subsection{Tanzania: Factors Affecting Sustainability of Technology Use in Secondary Education in Tanzania: The Effects of Collaborative Design Technology-Enhanced Science and Mathematics Lessons (Based on Kafyulilo et al. 2016)}

\subsubsection{Case Vignette}

Since 2002 the government of Tanzania has put efforts to ensure that schools with electricity connection have access to computers. However, access to the Internet was a problem. In most primary and secondary schools low-bandwidth modems were used to connect to the Internet. To promote the use of technology for teaching and learning the Information and Communication Technologies for Small and Medium-sized Enterprises (ICT-SME) project was launched in 2010. The intent of this project was to provide professional development for teachers to help them more effectively use the bandwidth that was available to them and integrate technology for teaching and learning. This project involved small, design based intervention studies, in which the researcher collaborated with practicing teachers to collaboratively design and implement technology-enhanced science and mathematics lessons. Teachers carried out the lessons with their students, reflected on them with the researcher, and engaged in an iterative redesign process to improve their practice. The collaborative design process consisted of two cycles of lesson design, implementation and refection-lasting about 10 weeks. In total three teams of in-service teachers at three different secondary schools (two government schools and one private school) participated in the ICT-SME project.

\subsubsection{Focus}

To find out the effect of collaborative design in researcher-teacher teams on sustained use of technology in teaching, the teachers and school administrators of the three participating schools were interviewed 6-12 months after participating in the design activities. The study focused on four factors contributing to sustained use of technology: characteristics of the intervention (e.g. Eickelmann 2011; Harvey and Hurworth 2006), personal factors (e.g. Harvey and Hurworth 2006), institutional factors (e.g. Buabeng-Andoh 2012; Eickelmann 2011) and technology factors (e.g. Collis and Moonen 2001).

\subsubsection{Discussion of Findings}

The findings showed that sustainability of teaching with technology in the three teams of in-service teachers differed. In two schools (one government and one private school) teachers did not teach with technology anymore. Contextual factors affected the lack of sustainability and differed between the schools. In the private school lack of support from the school administration and low motivation due to job insecurity and double employments affected sustainable use of technology. Also, in the government school, lack of support from the school management had impeded sustainable use of technology, in addition too few available technology tools, unreliable electricity, overcrowded classes, busy time schedules and no incentives made that the teachers no longer used the technology. The collaboration in the teacher team was facilitated by the school management and had sustained over time. Similar conditions (unreliable electricity, lack of tools, large class size) 
were also present in the second government school. Teachers in this second school used their own laptops to teach with technology. Students in this school asked the teachers and the school management to continue teaching with technology and the school management facilitated the teachers to support other teachers in the school to use technology. Students' influence had positively affected the school management resulting in sustained use of technology.

In this case, researchers and pre/in-service educators collaborated in both the design and implementation of technology enhanced lessons at three sites. Follow up research (6-18 months later) was used to directly examine the degree to which technology integration was sustained. The four factors that influenced sustainability were used to structure the analysis on whether use of technology was sustained at a given location: characteristics of the intervention, personal factors, institutional factors, and technology factors. What Ertmer (1999) referred to as first-order barriers were obstacles to implementation and sustainability in these schools (technology access, reliable electricity, class size, etc.). Although the technology integration efforts did not sustain, the teacher collaboration aspect of the project was supported by administration - and was sustained. In the school that did sustain technology integration, teachers took ownership-even using their own laptops in the classroom. Further, students were quite vocal in their support of their teachers' use of technology in the school, prompting administrators to more directly support and value their teachers' technology integration efforts.

\subsection{Canada: Scaling a Remote Networked School}

\subsubsection{Case Vignette}

The Remote Networked School (RNS) was a research and intervention initiative for 14 years (2002-2016). It began with a question, asked by a Quebec Government Deputy Minister: How can ICT help small rural schools enrich their learning environment in order to meet the requirements of the new national curriculum? Distance education courses not being an option due to Ministry's rulings, the original design emphasized coordination and collaboration between delocalized teachers and students. Teachers working in participating school districts were invited to co-design their RNS during a general meeting attended by all stakeholder groups (Ministry's representatives, school and school-district personnel and administrators, local social leaders, university-based researchers and graduate students). Researchers had been challenged to join the initiative by the knowledge transfer agency (CEFRIO) in charge of the initiative for the Ministry. They suggested concepts and tools related to collaborative learning and knowledge building (Scardamalia 2002; Scardamalia and Bereiter 2006), including a videoconferencing system for verbal exchanges and Knowledge Forum for written discourse. This initial model was adopted to begin with, and later adapted. Graduate students maintained an online presence in a virtual room, provided technical and pedagogical support, conducted data gathering activities, and filled an ethnographic template after each online meeting with teachers, school principals or school district personnel or administrator. Five design principles stood out: (1) Student empowerment in a democratic climate; (2) Authentic problems explored through idea diversity, (3) Improvement and diversification of ideas through participatory discourse; (4) Reference to reliable sources throughout the inquiry process and (5) Shared and in-context assessment throughout the process (Allaire and Lusignan 2011). Today, the RNS is characterized by activities involving students from distant classrooms that are co-designed by teachers with 
online/onsite external support. Teachers guide students as they engage in collaborative projects and inquiries or presentations to one another's team or classroom. Team-teaching occurs, special services are provided to students onsite/online, and different agencies conduct educational activities. Schools that are not remote and other Francophone regions with remote schools are adapting the model to their own context.

\subsubsection{Focus}

We looked at the RNS network for evidence of Clarke and Dede's (2009) five dimensions of scalability [Depth, Sustainability, Spread, Shift (in Ownership), and Evolution].

\subsubsection{Discussion of Findings}

The five dimensions of scalability were clearly present in the initiative. With regard to Depth, the initiative model gained support from the various stakeholder groups. Ethnographic data regarding context as well as local, national and international-level testing of learning outcomes in the participating schools were gathered on an iterative basis. Persuasive learning outcomes were obtained, especially when classrooms transformed into emerging knowledge building communities, e.g. vocabulary growth, types of questions asked and levels of explanation reached. This research design allowed for deep investigation into the characteristics of the innovation and how they evolved in different contexts. Seeing the original model being adapted in a number of different ways by school-district and school practitioners, the research and intervention team modified its own understanding and practice of ICT use for teaching and learning, and reinvested this learning into further iterations of the initiative.

Whether or not participating school districts applied integrally or not the original model, Government's funding was allocated to a growing number of them. This demonstrates flexibility that supports Scaling of the initiative. The RNS network now counts 35 school districts (about half of all Francophone school districts in Quebec, Canada), and involves over 300 schools and over 500 teachers. When a national curriculum is in place, the above results suggest that a school-university-government (SUNG) partnership is necessary for scaling ICT-based educational innovation.

CEFRIO had been instrumental in establishing a RNS Steering Committee, and coordinating its activities. Progressively, more responsibilities were taken on by the Steering Committee, composed of school district superintendents, a Ministry representative, and the RNS director. Teachers and researchers were invited to attend depending on what was on the agenda. Three years ago, there was a Shift in Ownership. CEFRIO left the Steering Group, and the latter kept developing the RNS network. While this does not necessarily imply that schools and teachers felt ownership, it does suggest a transition closer to the school context.

\section{Discussion}

Each of these examples illustrates a different educational technology innovation, but they are all relatively typical of changes expected in schools. While the four initiatives took on different forms, all were fundamentally addressing change related to how teachers were using digital technologies to support learning. As a result of the change initiatives having 
different approaches, we see a range of ways sustainability and scalability were both enabled and constrained over the life of the projects.

First, with regard to sustainability, we can see that participating teachers and schools were made aware of the initiative, but decisions to adopt or reject showed two different patterns. In the Ghana and Tanzania cases, initial participation and acceptance was much more structured and central to the interventions. This may also be a function of clear implementation objectives, or how they would be putting these new ideas to work in Mathematics and/or Science teaching. These cases show the importance of addressing Challenge 1, addressing key features of the innovation and context that support sustainability and scalability. It is necessary to consider how aspects of the innovation and context interact, which likely influence how innovative uses of technology can be adapted to promote sustainability and scale to other contexts. In both the Ghana and Tanzania cases, the innovation was not sustained primarily due to a number of contextual issues, such as organizational needs and resource limitations.

In the Australian and Canadian cases, the decision to adopt new technology-related teaching practice was much less structured. In the Canadian case, a model of implementation was proposed, but schools adopted it to suit their needs. In Australia, schools and teachers negotiated the use of the new laptops individually and in response to their own needs. This type of approach resulted in a less clear timeline of when and how technologies were adopted and implemented. It is possible that the evolution of these innovations allowed for strong feelings of ownership, and therefore supported scalability across a range of schools. However, in the Australian example, it was observed that teachers perceived other stakeholders, such as state and federal governments, were not seriously invested in the DER innovation, which weakened the potential for scalability by perceived lack of commitment from leadership. This issue points to the importance of Challenge 2 creating productive partnerships among stakeholders.

\subsection{Summary and Conclusions}

Technological innovation implementation is deeply contextual; with implementation of a given innovation playing out differently in different contexts and across multiple iterations within the context. We also identified key factors of sustainability and scalability and showed how they manifest in four different contexts through descriptive cases. Based on these findings, we now propose some short- and long-term recommendations that emerged from the TWG9 discussions:

Challenge 1: Establish productive research partnerships among stakeholders.

Short Term Recommendations

- Co-design research with real commitment and ownership from stakeholders at all levels.

- Develop and model strategies and procedures for developing productive partnerships that draw on existing research.

Long Term Recommendations

- Develop feedback loops to inform the process and maintain innovations which have been successful in other innovation contexts. 
- Help stakeholders at all levels better understand the value of research to support innovation (this requires building active communication strategies into the process).

- Develop iterative cycles of research that examine innovative technology integration that includes multiple stakeholders and attention to context.

Challenge 2: Identify research-informed approaches to technology integration that are sustainable and scalable.

Short Term Recommendations

- Provide opportunities and support for scholars to synthesize research from successfully scaled and sustained innovations into future innovation designs that address technology integration.

- Provide opportunities and support for scholars to extract best practice examples of successfully scaled and sustained innovations.

\section{Long Term Recommendation}

- Build a comprehensive body of knowledge about scalable and sustainable innovation designs and findings to inform decision-making and policy.

- Build on and adapt technology integration and innovation designs that have successfully scaled and sustained.

Challenge 3: Develop sustainable and scalable approaches to technology integration that are based on research literature rather than policy initiatives.

Short Term Recommendations

- Use research to deconstruct fads and communicate appropriate research findings to stakeholders.

- Develop a team of scholars and practitioners that can respond quickly to policy initiatives on the basis of accumulated research results.

\section{Long Term Recommendation}

- Actively involve policymakers and industry partners early and throughout the innovation process.

Innovation implementation changes when extended across and/or within contexts (Penuel et al. 2011; Rogers 2003). Therefore, top-down only approaches that seek fidelity of innovation implementation across situations are not consistent with what we know about issues of adaptation in the innovation diffusion process. This highlights the importance of Challenge 3 However, we strongly argue for a research perspective that identifies the core elements of an innovations, while respecting the mutual adaptation process inherent in implementation over time and across contexts. A key aspect of Challenge 1 will be to help teachers and school leadership makes sense of innovations and translate these into practical strategies of adaptation to support curriculum (see Janssen et al. 2015). As well, Challenge 2 focused on partnerships to address sustainability and scalability separately. This is an important distinction because the nature of adoption and adaptation in an innovation, while contributing, is different to concerns about sustainability scalability. This approach can significantly contribute to school and teacher change processes, to support and inform aspects 
of sustainability and elements of scalability, in relation to their core work of teaching and learning.

While sustainability and scalability are challenging and complex phenomena, and school change is a notoriously difficult challenge, TWG9 members remain optimistic that meaningful integration of technology can and will change the ways that we think about teaching, learning and schooling. Multiple interacting factors influence the change process, and challenges are often encountered when implementing curricular and pedagogical innovations that integrate technologies, which can be daunting. The ultimate goal is to integrate classroom technology use that is more meaningful, purposeful and relevant to students. We believe that establishing productive partnerships among stakeholders, identifying researchinformed approaches to technology integration that are sustainable and scalable, and developing sustainable and scalable approaches to technology integration that are based on research literature rather than policy initiatives can help inform this process.

Acknowledgements We would like to thank the organizers of EDUsummIT 17 and acknowledge the contributions of EDUsummIT 2017 Thematic Working Group 9 members Punya Mishra and Lynn Schrum during the EDUsummIT discussions in Borovets, Bulgaria.

\section{References}

Agyei, D. (2012). Preparation of pre-service teachers in Ghana to integrate Information and communication technology in teaching mathematics. Unpublished doctoral dissertation, University of Twente, Enschede, The Netherlands.

Agyei, D., \& Voogt, J. (2011). ICT use in the teaching of mathematics: Implications for professional development of pre-service teachers in Ghana. Education and Information Technologies, 16, 423-439.

Albion, P. R., Tondeur, J., Forkosh-Baruch, A., \& Peeraer, J. (2015). Teachers' professional development for ICT integration: Towards a reciprocal relationship between research and practice. Education and Information Technologies, 20(4), 655-673.

Allaire, S., \& Lusignan, G. (2011). Enseigner et apprendre en réseau: Collaborer entre écoles distantes à l'aide des TIC. Anjou: Éditions CEC.

Baldwin, T. T., \& Ford, J. K. (1988). Transfer of training: A review and directions for future research. Personnel Psychology, 41, 63-105.

Bebell, D., \& O'Dwyer, L. M. (2010). Educational outcomes and research from 1:1 computing settings. Journal of Technology, Learning, and Assessment, 9(1), 4-14.

Buabeng-Andoh, C. (2012). Factors influencing teachers' adoption and integration of information and communication technology into teaching: A review of the literature. International Journal of Education and Development Using Information and Communication Technology, 8(1), 136-155.

Clarke, J., \& Dede, C. (2009). Design for scalability: A case study of the River City curriculum. Journal of Science Education and Technology, 18(4), 353-365.

Coburn, C. E. (2003). Rethinking scale: Moving beyond numbers to deep and lasting change. Educational Researcher, 32(6), 3-12.

Collis, B., \& Moonen, J. (2001). Flexible learning in a digital world: Experiences and expectations. London: Kogan Page.

Cuban, L. (2002). Oversold and underused: Computers in the classroom. Cambridge, MA: Harvard University Press.

Darling-Hammond, L., Wei, R. C., Andree, A., Richardson, N., \& Orphanos, S. (2009). Professional learning in the learning profession: A status report on teacher development in the United States and abroad. Oxford, OH: National Staff Development Council.

Dede, C. (2006). Scaling up: Evolving innovations beyond ideal settings to challenging contexts of practice. In R. K. Sawyer (Ed.), Cambridge handbook of the learning sciences (pp. 551-566). Cambridge: Cambridge University Press.

Department of Education Employment and Workplace Relations. (2012). Digital education revolutionOverview. Retrieved September 20, 2013, from http://www.deewr.gov.au/Schooling/DigitalEducatio nRevolution/Pages/default.aspx 
Dickard, N. (Ed.) (2003). The sustainability challenge: Taking EdTech to the next level. Chicago: Joyce Foundation. http://www2.edc.org/CCT/admin/. Accessed 14 Feb 2018.

Dunleavy, M., Dexter, S., \& Heinecke, W. (2007). What added value does a 1:1 student to laptop ratio bring to technology-supported teaching and learning? Journal of Computer Assisted learning, 23(5), 440-452. https://doi.org/10.1111/j.1365-2729.2007.00227.x.

Eickelmann, B. (2011). Supportive and hindering factors to a sustainable implementation of ICT in schools. Journal of Educational Research Online, 3(1), 75-103.

Ertmer, P. A. (1999). Addressing first- and second-order barriers to change: Strategies for technology integration. Educational Technology Research and Development, 47(4), 47-61.

Ertmer, P. A., \& Ottenbreit-Leftwich, A. T. (2010). Teacher technology change: How knowledge, confidence, beliefs, and culture intersect. Journal of Research on Technology in Education, 42(3), 255284. https://doi.org/10.1080/15391523.2010.10782551.

Fishman, B., Marx, R. W., Blumenfeld, P., Krajcik, J., \& Soloway, E. (2004). Creating a framework for research on systemic technology innovations. The Journal of the Learning Sciences, 13(1), 43-76.

Fleener, M. J. (2016). Re-searching methods in educational research: A transdisciplinary approach. In M. Koopmans \& D. Stamovlasis (Eds.), Complex dynamical systems in education: Concepts, methods and applications (pp. 9-21). Cham: Springer. https://doi.org/10.1007/978-3-319-27577-2_2.

Fullan, M. (2009). Large-scale reform comes of age. Journal of Educational Change, 10(2-3), 101-113. https://doi.org/10.1007/s10833-009-9108-z.

Fullan, M. (2015). The new meaning of educational change (5th ed.). New York, NY: Teachers College Press.

Gao, N., \& Murphy, P. (2016). Upgrading technology infrastructure in California's schools. Sacramento, CA: Public Policy Institute of California.

Greenhow, C., Robelia, B., \& Hughes, J. E. (2009). Learning, teaching, and scholarship in a digital age. Educational Researcher, 38(4), 246-259. https://doi.org/10.3102/0013189X09336671.

Hargreaves, A., \& Fink, D. (2000). The three dimensions of reform. Educational Leadership, 57(7), 30-33.

Hargreaves, A., Boyle, A., \& Harris, A. (2014). Uplifting leadership: How organizations, teams, and communities raise performance. San Francisco: Jossey Bass.

Harvey, G., \& Hurworth, R. (2006). Exploring programme sustainability: Identifying factors in two educational initiatives in Victoria. Evaluation Journal of Australasia, 6(1), 36-44.

Howard, S. K. (2011). Affect and acceptability: Exploring teachers' technology-related risk perceptions. Educational Media International, 48(4), 261-273. https://doi.org/10.1080/09523987.2011.632275.

Howard, S. K., \& Gigliotti, A. (2016). Having a go: Looking at teachers' experience of risk-taking in technology integration. Education and Information Technologies, 21(5), 1351-1366. https://doi. org/10.1007/s10639-015-9386-4.

Howard, S. K., \& Thompson, K. (2016). Seeing the system: Dynamics and complexity of technology integration in secondary schools. Education and Information Technologies, 21(6), 1877-1894. https://doi.org/10.1007/s10639-015-9424-2.

Janssen, F., Westbroek, H., \& Doyle, W. (2015). Practicality studies: How to move from what works in principle to what works in practice. Journal of the Learning Sciences, 24(1), 176-186.

Jonassen, D. H. (1995). Supporting communities of learners with technology: A vision for integrating technology with learning in schools. Educational Technology, 35(4), 60-63.

Kafyulilo, A., Fisser, P., \& Voogt, J. (2016). Factors affecting teachers' continuation of technology use in teaching. Education and Information Technologies, 21, 535-1554.

Kirkwood, A., \& Price, L. (2013). Examining some assumptions and limitations of research on the effects of emerging technologies for teaching and learning in higher education. British Journal of Educational Technology, 44(4), 536-543.

Koba, M. (2015). Education tech funding soars-But is it working in the classroom? Retrieved from http://fortune.com/2015/04/28/education-tech-funding-soars-but-is-it-working-in-the-classroom/. Accessed 20 Feb 2018.

Livingstone, S. (2012). Critical reflections on the benefits of ICT in education. Oxford Review of Education, 38(1), 9-24. https://doi.org/10.1080/03054985.2011.577938.

McCandless, J. (2015). U.S. education institutions spend \$6.6 Billion on IT in 2015. Retrieved from http://www.centerdigitaled.com/higher-ed/US-Education-Institutions-Spend-66-Billion-on-ITin-2015.html. Accessed 14 Feb 2018.

Niederhauser, D. S., \& Lindstrom, D. L. (2018). Instructional technology integration models and frameworks: Diffusion, competencies, attitudes, and dispositions. In J. Voogt, G. Knezek, R. Christensen, \& K. W. Lai (Eds.), Handbook of information technology in primary and secondary education. Cham: Springer. 
Niederhauser, D. S., Mishra, P., Agyei, D., Cox, M., Howard, S., Laferriere, T., et al. (2017). Supporting sustainability and scalability in educational technology initiatives: Research informed practice. In K. Lai, J. Voogt, \& G. Knezek (Eds.), Rethinking learning in a digital age: Edusummit 2017 Summary Reports (pp. 71-76). Borovets: UNESCO. ISBN 978-0-473-42542-5.

Owston, R. D. (2003). School context, sustainability, and transferability of innovation. In R. Kozma (Ed.), Technology, innovation and educational change: A global perspective. Eugene, OR: ISTE.

Penuel, W. R., Fishman, B. J., Haugan Cheng, B., \& Sabelli, N. (2011). Organizing research and development at the intersection of learning, implementation, and design. Educational Researcher, 40(7), 331-337.

Purcell, K., Heaps, A., Buchanan, J., \& Friedrich, L. (2013). How teachers are using technology at home and in their classrooms. Washington, DC: Pew Research Center's Internet \& American Life Project. Retrieved from http://www.pewinternet.org/2013/02/28/how-teachers-are-using-technology-at-homeand-in-their-classrooms/. Accessed 14 Feb 2018.

Reeves, T. C., \& Reeves, P. M. (2015). Educational technology research in a VUCA world. Educational Technology, 55(2), 26-30.

Rogers, E. M. (2003). Diffusion of innovation. New York: Simon and Schuster.

Sandholtz, J. H., \& Ringstaff, C. (1996). Teacher change in technology-rich classrooms. In C. Fisher, D. Dwyer \& K. Yocam (Eds.), Education and technology: Reflections on computing in classrooms. San Francisco: Jossey-Bass.

Scardamalia, M. (2002). Collective cognitive responsibility for the advancement of knowledge. In B. Smith (Ed.), Liberal education in a knowledge society (pp. 67-98). Chicago: Open Court.

Scardamalia, M., \& Bereiter, C. (2006). Knowledge building: Theory, pedagogy, and technology. In K. Sawyer (Ed.), Cambridge handbook of the learning sciences (pp. 97-118). New York: Cambridge University Press.

Sherry, L. (1998). An integrated technology adoption and diffusion model. International Journal of Educational Telecommunications, 4(2), 113-145.

Stringfield, S., \& Datnow, A. (1998). Scaling up school restructuring designs in urban schools. Education and Urban Society, 30(3), 269-276.

Teo, T., \& Noyes, J. (2008). Computers in human behavior development and validation of a computer attitude measure for young students (CAMYS), 24, 2659-2667. https://doi.org/10.1016/j.chb.2008.03.006.

Todorova, A., \& Osburg, T. (2009). Factors for the sustainability of a teacher professional development programme for technology integration. Paper presented at the London international conference on education, London.

Van Veen, K., \& Sleegers, P. (2006). How does it feel? Teachers' emotions in a context of change. Journal of Curriculum Studies, 38(1), 85-111. https://doi.org/10.1080/00220270500109304References.

Voogt, J., Laferrière, T., Breuleux, A., Itow, R., Hickey, D., \& McKenney, S. (2015). Collaborative design as a form of professional development. Instructional Science, 43, 259-282.

Wiske, M. S., \& Perkins, D. (2005). Dewey goes digital: Scaling up constructivist pedagogies and the promise of new technologies. In C. Dede, J. Honan, \& L. Peters (Eds.), Scaling up success: Lessons learned from technology-based educational improvement. New York: Jossey-Bass. 